\title{
Pengaruh Keputusan Investasi, Keputusan Pendanaan, Dan Kebijakan Dividen Terhadap Nilai Perusahaan (Pada Perusahaan Manufaktur sector Industri Barang Konsumsi yang Terdaftar di Bursa Efek Indonesia Tahun 2016-2019)
}

\author{
Risma Apriani ${ }^{1}$, Mohamad Zulman Hakim², Dirvi Surya Abbas ${ }^{3}$ \\ Universitas Muhammadiyah Tangerang \\ rismaapriani6@gmail.com
}

\begin{abstract}
Abstrak: Tujuan penelitian ini untuk menguji pengaruh variabel keputusan investasi, keputusan pendanaan, dan kebijakan dividen. .Baik secara simultan maupun parsial terhadap variabel nilai perusahaan. Penelitian ini bersifat kuantitatif. . Teknik pemilihan sampel menggunakan purposive sampling. Jumlah perusahaan manufaktur subsektor industry barang konsumsi di BEI selama periode 2016-2019 yang masuk sebagai daftar populasi adalah sebanyak 15 perusahaan, kemudian didapatkan sampel sebanyak 60 . Penentuan jumlah sampel dalam penelitian ini menggunakan metode sekunder. Teknik analisis data menggunakan regresi data panel dengan program EVIEWS 9.0. Hasil penelitian ini menemukan bahwa secara parsial keputusan investasi berpengaruh dan keputusan pendanaan berpengaruh terhadap nilai perusahaan, sedangkan kebijakan dividen tidak berpengaruh terhadap nilai perusahaan
\end{abstract}

Kata kunci: keputusan investasi, keputusan pendanaan, kebijakan dividen

Kondisi perekonomian di Negara Indonesia saat ini telah mengalami banyak perkembangan. Perekonomian yang meningkat ini tercermin dari perkembangan dunia bisnis, yang membuat banyak perusahaan menjadi bersaing meningkatkan kualitas nilai perusahaan mereka. Khususnya persaingan di perusahaan manufaktur sector industry barang konsumsi yang banyak bersaing untuk memakmurkan para pemegang saham mereka melalui peningkatan nilai perusahaan.

Menurut Harmono (2009:233), nilai Perusahaan adalah kinerja perusahaan yang dicerminkan oleh harga saham yang dibentuk oleh permintaan dan penawaran pasar modal yang merefleksikan penilaian masyarakat terhadap kinerja perusahaan. Nilai suatu perusahaan dipengaruhi oleh banyak faktor-faktor. Contoh faktor-faktor yang mempengaruhi nilai perusahaan diantara lain adalah Keputusan Investasi, Keputusan Pendanaan dan Kebijakan Dividen. Pentingnya nilai perusahaan terhadap banyak pihak, sehingga faktor-faktor yang mempengaruhi nilai perusahaan berdasarkan informasi keuangan yang dipublikasikan oleh perusahaan perlu untuk diidentifikasi

fungsi manajemen keuangan terbagi menjadi beberapa beberapa keputusan utama, diantaranya adalah keputusan investasi (Van Horne \& Wachowicz 2009). Keputusan investasi yang benar diharapkan dapat memberikan pertumbuhan yang baik untuk perusahaan maupun investor. Keputusan pendanaan adalah keputusan yang harus diambil manajer keuangan suatu perusahaan untuk mendanai investasi-investasi yang dilakukan oleh suatu perusahaan. 
Kebijakan dividen adalah keputusan atau kebijakan yang berkaitan dengan berapa banyak jumlah laba yang harus dibayarkan kepada para pemegang saham dan berapa banyak jumlah yang harus ditahan sebagai tambahan modal perusahaan. jumlah dividen yang dibagikan akan berpengaruh pada besar kecil nya laba yang ditahan.

Teori keagenan menjelaskan hubungan antara pemegang saham (shareholders) sebagai prinsipal dan manajemen sebagai agen. Manajer diberi kekuasaan oleh para pemilik perusahaan, yaitu pemegang saham untuk membuat keputusan, dimana hal ini menciptakan potensi konflik kepentingan (Brigham dan Houston, 2006: 26). Masalah keagenan (agency problem) merupakan masalah yang timbul akibat konflik kepentingan antara manajer (agen pemegang saham) dengan pemegang saham karena adanya pemisahan tugas manajemen perusahaan dengan para pemegang saham (Keown at al,2008:18). Masalah keagenan biasanya tejadi apabila manajer perusahaan memiliki proporsi kepemilikan saham kurang dari $100 \%$ sehingga manajer cenderung bertindak untuk mengjar kepentingan dirinya dalam pengambilan keputusan keuangan perusahaan dan tidak berdasarkan pada memaksimalkan nilai perusahaan.

Menurut (Sulis Setyowati, 2016) Keputusan investasi berpengaruh signifikan terhadap nilai perusahaan. Sedangkan menurut (Luh putu utami, I Wayan Pradnyantha 2018) Keputusan Investasi tidak berpengaruh pada nilai perusahaan. Menurut (inasfatin, 2017) keputusan pendanaan berpengaruh positif terhadap nilai perusahaan, sedangkan menurut (Merina Salama, Paulina Van Rate, Victoria N.Untu) Keputusan pendanaan tidak berpengaruh signifikan pada nilai perusahaan.Kemudian menurut (Luh putu utami, I wayan Pradnyantha, 2018) Kebijakan dividen berpengaruh positif terhadap nilai perusahaan. Sedangkan menurut (Inasfatin, 2017) kebijakan deviden tidak berpengaruh terhadap nilai perusahaan

Adapun Tujuan Penelitian ini untuk membuktikan secara empiris pengaruh Keputusan Investasi, Keputusan Pendanaan, Kebijakan Dividen terhadap nilai perusahaan perusahaan sector Manufactur sekor industri barang konsumsi periode 2016-2019

\section{METODE}

\section{A. Pendekatan Penelitian}

Dalam penelitian ini jenis pendekatan penelitian yang digunakan adalah penelitian kuantitatif dengan menggunakan data sekunder, yaitu data yang diperoleh dari Bursa Efek Indonesia (BEI). Metode penelitian kuantitatif dapat diartikan sebagai metode penelitian yang berlandaskan pada filsafat positivism, digunakan untuk meneliti pada populasi atau sampel tertentu, pengumpulan data menggunakan instrument penelitian, analisis data bersiffat kuantitatif atau statistic dengan tujuan untuk menguji hipotesis yang telah ditetapkan (Sugiyono, 2016) 


\section{B. Metode Pengambilan Sampel}

Dalam penelitian ini, teknik pengambilan sampel yang digunakan adalah nonprobability sampling, dengan metode purposive sampling. Sugiyono $(2012,68)$, purposive sampling adalah teknik penentuan sampel dengan pertimbangan tertentu. Adapun kriteria data yang digunakan dalam penelitian ini adalah Perusahaan manufaktur sector industry barang konsumsi yang terdaftar di BEl

C. Metode Analisis Data

1. Analisis Deskriptif

Analisis deskriptif adalah analisis yang digunakan untuk menganalisis data dengan cara mendeskripsikan atau menggambarkan data yang telah terkumpul sebagaimana adanya tanpa bermaksud membuat kesimpulan yang berlaku untuk umum atau generalisasi.

2. Estimasi Regresi Data Panel

Menurut (Winarno, 2011), data panel dapat didefinisikan sebagai gabungan antara datasilang (cross section) dengan data runtut waktu (time series). Dan menurut (Basuki \& Prawoto, 2016) dalam (lutfi, 2017) dalam mengestimasi model regresi data panel terdapat 3 pendekatan yang dapat digunakan yaitu pendekatan ordinary least square (OLS), atau Commont Effect Model (CEM), Fixed Effect Model (FEM), dan pendekatan general least squared (GLS) atau random effect model (REM).

3. Teknik Pemilihan Model Regresi Data Panel

Untuk memilih model yang paling tepat dalam mengelola data panel, terdapat beberapa pengujian yang dilakukan, antara lain:

a. Uji Chow

Uji Chow digunakan untuk memilih antara metode Common Effect dan metode Fixed Effect, dengan ketentuan pengambilan keputusan sebagai berikut:

$\mathrm{HO}$ : Metode common effect

$\mathrm{H} 1$ : Metode fixed effect

Jika nilai $p$-value cross section Chi Square $<\alpha=5 \%$, atau nilai probability ( $p$ - value) $F$ test $<\alpha=5 \%$ maka Ho ditolak atau dapat dikatakan bahwa metode yang digunakan adalah metode fixed effect. Jika nilai $p$-value cross section Chi Square $\geq \alpha=5 \%$, atau nilai probability ( $p$-value) Ftest $\geq \alpha=5 \%$ maka $\mathrm{HO}$ diterima, atau dapat dikatakan bahwa metode yang digunakan adalah metode common effect.

b. Uji Hausman

Uji Hausman dapat didefinisikan sebagai pengujian statistik untuk memilih apakah model Fixed Effect atau Random Effect yang paling tepat digunakan. Pengujian uji Hausman dilakukan dengan hipotesis berikut:

HO : Random Effect Model

H1 : Fixed Effect Model 
c. Uji Lagrange Multiplier

Untuk mengetahui apakah model Random Effect lebih baik daripada metodeCommon Effect (OLS) digunakan uji Lagrange Multiplier (LM).Uji signifikasi Random Effectini dikembangkan oleh Breusch Pagan. Metode Bruesch Pagan untuk menguji signifikasi Random Effect didasarkan pada nilai residual dari metode Common Effect.

4. Uji Hipotesis
a. Uji F
Uji F digunakan untuk mengetahui apakah seluruh variabel independen secara bersama-sama berpengaruh terhadap variabel dependen pada tingkat signifikansi $0,05(\alpha=5 \%)$. Pengujian semua koefisien regresi secara bersama-sama dilakukan dengan uji $\mathrm{F}$ dengan pengujian sebagai berikut:
Hipotesis:
$\mathrm{HO}$ : Bila probabilitas $\beta 1>0,05$ artinya secara bersama-sama tidak ada pengaruh variabel independen terhadap variabel dependen.
$\mathrm{H} 1$ : Bila probabilitas $\beta 1<0,05$ artinya secara bersama-sama ada pengaruh variabel independen terhadap variabel dependen.

b. Uji Koefisien Determinasi (R-Square)

Nilai koefisien determinasi (R2) digunakan untuk mengukur seberapa besar variasi dari variabel dependen $(Y)$ dapat dijelaskan oleh variabel independen $(X)$. Bila nilai koefisien determinasi $=0(R 2=0)$, artinya variasi dari variabel dependen tidak dapat dijelaskan oleh variabel independen. Sementara bila $\mathrm{R} 2=1$, artinya variasi dari variabel dependen secara keseluruhan dapat dijelaskan oleh variabel independen. Dengan kata lain jika R2 mendekati 1 (satu), maka variabel independen mampu menjelaskan perubahan variabel dependen. Tetapi jika R2 mendekati 0 , maka variabel independen tidak mampu menjelaskan variabel dependen.

c. Uji Parsial (t-statistik)

Uji-t statistik adalah uji parsial (individu) dimana uji ini digunakan untuk menguji seberapa baik variabel independen dapat menjelaskan variabel dependen secara individu. Pada tingkat signifikansi 0,05 (5\%) dengan menganggap variabel independen bernilai konstan. Pengujian t-statistik dilakukan dengan hipotesis sebagai berikut:

Hipotesis:

Ho: Bila probabilitas $\beta 1>0,05$ artinya tidak ada pengaruh variabel independen terhadap variabel dependen.

$\mathrm{H} 1$ : Bila probabilitas $\beta 1<0,05$ artinya ada pengaruh variabel independen terhadap variabel dependen.

5. Analisis Regresi Data Panel

Penelitian ini menggunakan analisis regresi berganda. Dalam regresi berganda digunakan untuk mengetahui apakah hipotesis penelitian terbukti signifikan atau tidak gignifikan, dengan persamaan sebagai berikut :

$Y=\alpha+\beta 1 X 1 i t+\beta 2 X 2 i t+\beta 3 X 3 i t+\ldots+\beta n X n i t+$ eit 


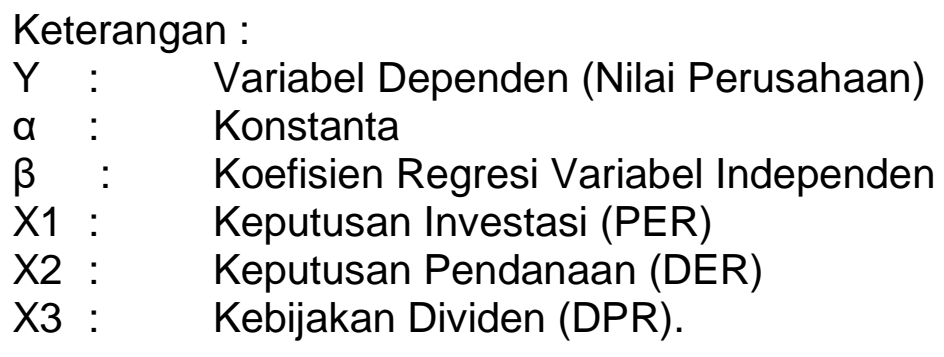

\section{PEMBAHASAN}

1. Analisis Statistik Deskriptif.

\begin{tabular}{|l|c|c|c|c}
\hline & PVB & PER & DER & DPR \\
\hline Mean & 9.100167 & 23.77100 & 0.691167 & 0.548500 \\
\hline Median & 2.930000 & 22.60000 & 0.510000 & 0.455000 \\
\hline Maximum & 82.44000 & 60.89000 & 2.650000 & 4.920000 \\
\hline Minimum & 0.650000 & 1.660000 & 0.080000 & 0.140000 \\
\hline Std. Dev. & 16.66315 & 10.88013 & 0.578646 & 0.610517 \\
\hline Skewness & 2.864676 & 0.902112 & 1.626058 & 6.248894 \\
\hline Kurtosis & 10.65983 & 4.171033 & 5.473478 & 45.34614 \\
\hline & & & & \\
\hline Jarque-Bera & 228.7461 & 11.56636 & 41.73586 & 4873.475 \\
\hline Probability & 0.000000 & 0.003079 & 0.000000 & 0.000000 \\
\hline & & & & \\
\hline Sum & 546.0100 & 1426.260 & 41.47000 & 32.91000 \\
\hline Sum Sq. Dev. & 16381.96 & 6984.255 & 19.75502 & 21.99117 \\
\hline & & & & \\
\hline Observations & 60 & 60 & 60 & 60 \\
\hline
\end{tabular}

Nilai Mean terbesar dialami oleh variabel PER yaitu sebesar 23,77100 sementara variabel yang memiliki mean terkecil yaitu DPR sebesar 0,548500 . Nilai Median terbesar dialami oleh variabel PER yaitu sebesar 22,60000 sementara DPR memiliki median terkecil sebesar 0,455000 . Nilai Maximum terbesar ada di variabel PVB yaitu sebesar 82,440000 sementara maximum terkecil ada di variabel DER yaitu sebesar 2,65000. Nilai Minimum terbesar dialami oleh variabel PER yaitu sebesar 1,660000, sementara Minimum terkecil dialami oleh variabel DPR sebesar 0,140000. Nilai Standar Deviasi terbesar dialami oleh variabel PVB 16,66315 yang berarti bahwa variabel IOS memiliki tingkat resiko yang lebih tinggi yang mengalami perubahan dibandingkan dengan variabel-variabel yang lain selama periode penelitian. Sementara variabel DER memiliki tingkat resiko yang paling rendah, yaitu sebesar 0,578646. Nilai Skewness yang memiliki nilai di atas 0 (nol) yaitu variabel PVB, DER, dan DPR yang berarti bahwa asimetri distribusi data di sekitar mean tidak normal. Nilai Kurtosis untuk variabel PVB, PER, DER, dan DPR memiliki nilai Kurtosis lebih dari 3 yang berarti bahwa ketinggian distribusi data tidak normal. uji Jarque-Bera didistribusi dengan X2 dengan derajat bebas (degree of freedom) sebesar 2. Probability menunjukkan kemungkinan nilai JarqueBera melebihi (dalam nilai absolut) nilai terobservasi di bawah hipotesis nol. Nilai probabilitas yang kecil cenderung mengarahkan pada penolakan hipotesis nol distribusi normal. 
2. Estimasi Regresi Data Panel

a. Common Effect Model (CEM)

Dependent Variable: PVB

Method: Panel Least Squares

Date: 11/21/20 Time: 08:38

Sample: 20162019

Periods included: 4

Total panel (balanced) observations: 60

\begin{tabular}{lrlrr}
\hline \hline \multicolumn{1}{c}{ Variable } & Coefficient & Std. Error & t-Statistic & Prob. \\
\hline \hline C & -14.91256 & 3.110750 & -4.793880 & 0.0000 \\
PER & 0.481922 & 0.127738 & 3.772734 & 0.0004 \\
DER & 18.42753 & 2.410679 & 7.644122 & 0.0000 \\
DPR & -0.327319 & 2.000422 & -0.163625 & 0.8706 \\
\hline \hline R-squared & 0.701889 & Mean dependent var & 9.100167 \\
Adjusted R-squared & 0.685918 & S.D. dependent var & 16.66315 \\
S.E. of regression & 9.338525 & Akaike info criterion & 7.370514 \\
Sum squared resid & 4883.651 & Schwarz criterion & 7.510137 \\
Log likelihood & -217.1154 & Hannan-Quinn criter. & 7.425128 \\
F-statistic & 43.94974 & Durbin-Watson stat & 0.471343 \\
Prob(F-statistic) & 0.000000 & & & \\
\hline
\end{tabular}

b. $\quad$ Fixed Effect Model (FEM)

View[Proc| Object][Print| Name [Freeze][Estimate[Forecast] Stats][Resids]

Dependent Variable: PvB

Method: Panel Least Squares

Sample: 20162019

Periods included: 4

Cross-sections included: 15

\begin{tabular}{|c|c|c|c|c|}
\hline Variable & Coefricient & Std. Error & t-Statistic & Prob. \\
\hline $\begin{array}{l}\text { C } \\
\text { PER } \\
\text { DER } \\
\text { DPR }\end{array}$ & $\begin{array}{r}-1.853327 \\
0.225927 \\
7.969930 \\
0.135724\end{array}$ & $\begin{array}{l}2.071302 \\
0.073504 \\
1.778899 \\
0.804664\end{array}$ & $\begin{array}{r}-0.894764 \\
3.073674 \\
4.480260 \\
0.168672\end{array}$ & $\begin{array}{l}0.3760 \\
0.0037 \\
0.0001 \\
0.8669\end{array}$ \\
\hline \multicolumn{5}{|c|}{ Effects Specification } \\
\hline \multicolumn{5}{|c|}{ Cross-section fixed (dummy variables) } \\
\hline $\begin{array}{l}\text { R-squared } \\
\text { Adjusted R-squared } \\
\text { s.E. of regression } \\
\text { Sum squared resid } \\
\text { Log likelihood } \\
\text { F-statistic } \\
\text { Prob(F-statistic) }\end{array}$ & $\begin{array}{l}0.971578 \\
0.960074 \\
3.329554 \\
465.6090 \\
-146.6064 \\
84.45446 \\
0.000000\end{array}$ & $\begin{array}{l}\text { Mean depen } \\
\text { S.D. depend } \\
\text { Akaike info c } \\
\text { Schwarz crite } \\
\text { Hannan-Quir } \\
\text { Durbin-Wats }\end{array}$ & $\begin{array}{l}\text { nt var } \\
\text { itvar } \\
\text { erion } \\
\text { on } \\
\text { criter. } \\
\text { stat }\end{array}$ & $\begin{array}{l}9.100167 \\
16.66315 \\
5.486879 \\
6.115182 \\
5.732643 \\
3.904195\end{array}$ \\
\hline
\end{tabular}

C. Random Effect Model (REM)

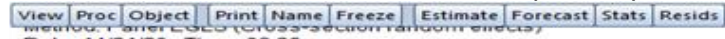

Date: 11/21/20 Time: $08: 39$

Sample: 20162019

Cross-sections included: 15

Total panel (balanced) observations: 60
Swamy and Arora estimator of component variances

\begin{tabular}{|c|c|c|c|c|}
\hline variable & Coemcient & sta. Error & t-Statistic & Prob. \\
\hline $\begin{array}{l}\text { C } \\
\text { PER } \\
\text { DER } \\
\text { DPR }\end{array}$ & $\begin{array}{r}-4.056938 \\
0.263845 \\
9.828402 \\
0.168050\end{array}$ & $\begin{array}{l}3.023355 \\
0.071356 \\
1.671190 \\
0.800795\end{array}$ & $\begin{array}{r}-1.341866 \\
3.697582 \\
5.881081 \\
0.209854\end{array}$ & $\begin{array}{l}0.1851 \\
0.0005 \\
0.0000 \\
0.8345\end{array}$ \\
\hline \multicolumn{3}{|c|}{ Efrects Specification } & S.D. & Rho \\
\hline $\begin{array}{l}\text { Cross-section random } \\
\text { Idiosymcratic random }\end{array}$ & & & $\begin{array}{r}8.929290 \\
3.3295544 \\
\end{array}$ & $\begin{array}{l}0.8779 \\
0.1221 \\
\end{array}$ \\
\hline \multicolumn{5}{|c|}{ Weighted Statistics } \\
\hline $\begin{array}{l}\text { R-squared } \\
\text { Adjusted R-squared } \\
\text { S.E. of regression } \\
\text { F-statistic } \\
\text { Prob(F-statistic) }\end{array}$ & $\begin{array}{l}0.481240 \\
0.453450 \\
3.569262 \\
17.31660 \\
0.000000\end{array}$ & $\begin{array}{l}\text { Mean depen } \\
\text { S.D. depend } \\
\text { Sum square } \\
\text { Durbin-wats }\end{array}$ & & $\begin{array}{l}1.667895 \\
4.827956 \\
713.4192 \\
2.448471\end{array}$ \\
\hline
\end{tabular}

3. Teknik Pemilihan Model Regresi Data Panel

a. Uji Chow

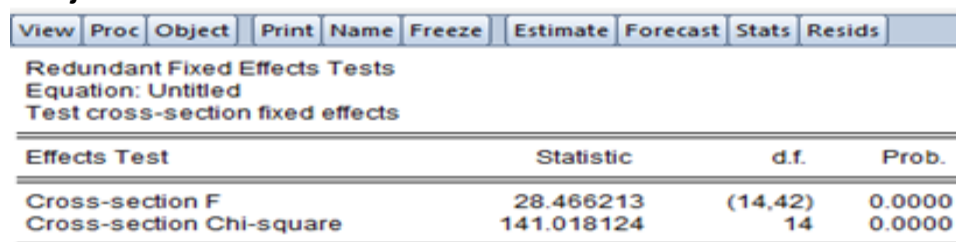


Hasil Uji Chow didapatkan FEM, karena Cross-section F dan Cross-section Chi-square $<0,05$

b. Uji Hausman

\begin{tabular}{|c|c|c|c|c|c|c|c|c|c|c|}
\hline View & Proc & Object & Print & Name & Freeze & Estimate & Forecast & Stats & Resids & \\
\hline \multicolumn{11}{|c|}{$\begin{array}{l}\text { Correlated Random Effects - Hausman Test } \\
\text { Equation: EQ03 } \\
\text { Test cross-section random effects }\end{array}$} \\
\hline \multicolumn{5}{|c|}{ Test Summary } & \multicolumn{2}{|c|}{ Chi-Sq. Statistic } & \multicolumn{2}{|c|}{ Chi-Sq. d.f. } & & Prob. \\
\hline \multicolumn{5}{|c|}{ Cross-section random } & & 11.35358 & 83 & & 3 & 0.0100 \\
\hline
\end{tabular}

Cross-section random effects test comparisons:

Hasil Uji Hausman didapaatkan FEM, karena Cross-Section random nya $<0,05$.

c. Uji Lagrange Multiplier

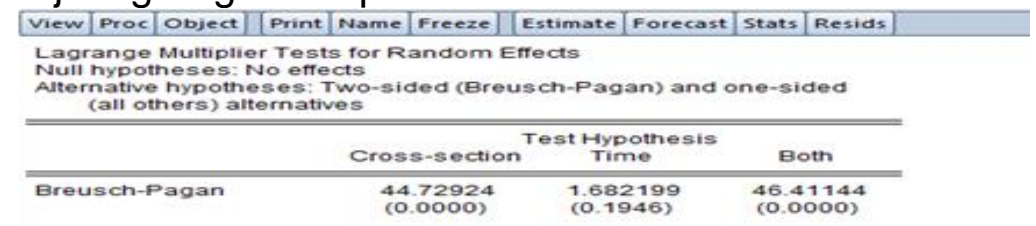

Hasil Uji Lagrange Multiplier didapatkan REM, karena cross-section $<0,05$

4. Kesimpulan Model

Digunakan model Fixed Effect Model karena memenangkan Uji

Chow dan Uji Hausman

\section{A. Uji Asumsi Klasik}

1. Uji Multikolineritas

\begin{tabular}{|c|c|c|c|c|c|c|c|c|c|}
\hline View & Proc & Object & Print & Name & Freeze & Sample & Sheet & Stats & Spec \\
\hline & & & \multicolumn{2}{|l|}{ PVB } & \multicolumn{2}{|c|}{ PER } & \multicolumn{2}{|l|}{ DER } & DPR \\
\hline \multicolumn{2}{|r|}{ PVB } & & \multicolumn{2}{|c|}{1.000000} & \multicolumn{2}{|c|}{0.623808} & \multicolumn{2}{|c|}{0.790936} & 0.044758 \\
\hline \multicolumn{2}{|r|}{ PER } & & \multicolumn{2}{|c|}{0.623808} & \multicolumn{2}{|c|}{1.000000} & \multicolumn{2}{|c|}{0.483203} & 0.005839 \\
\hline \multicolumn{2}{|r|}{ DER } & & \multicolumn{2}{|c|}{0.790936} & \multicolumn{2}{|c|}{0.483203} & \multicolumn{2}{|c|}{1.000000} & 0.085813 \\
\hline \multicolumn{2}{|r|}{ DPR } & & \multicolumn{2}{|c|}{0.044758} & \multicolumn{2}{|c|}{0.005839} & \multicolumn{2}{|c|}{0.085813} & 1.000000 \\
\hline
\end{tabular}

Dari output diatas dapat dilihat tidak terdapat variabel independen yang memiliki nilai lebih dari 0,8 , sehingga dapat disimpulkan tidak terjadi multikolinearitas dalam model regresi

2. Uji Heteroskedastisitas

\begin{tabular}{lrrr}
\hline \multicolumn{1}{c}{ Test } & Statistic & d.f. & Prob. \\
\hline \hline Breusch-Pagan LM & 124.3621 & 105 & 0.0956 \\
Pesaran Scaled LM & 0.301016 & & 0.7634 \\
Bias-corrected scaled LM & -2.198984 & & 0.0279 \\
Pesaran CD & 0.863627 & & 0.3878 \\
\hline \hline
\end{tabular}

Berdasarkan output diatas dapat dilihat bahwa nilai prob breusch-pagan LM 0,0956 < 0,05 maka dapat disimpulkan bahwa model regresi tidak terjadi heteroskedastisitas. 


\section{B. Uji Hipotesis}

a. Uji F

\begin{tabular}{lrll}
\hline \hline R-squared & 0.971578 & Mean dependent var & 9.100167 \\
Adjusted R-squared & 0.960074 & S.D. dependent var & 16.66315 \\
S.E. of regression & 3.329554 & Akaike info criterion & 5.486879 \\
Sum squared resid & 465.6090 & Schwarz criterion & 6.115182 \\
Log likelihood & -146.6064 & Hannan-Quinn criter. & 5.732643 \\
F-statistic & 84.45446 & Durbin-Watson stat & 3.904195 \\
Prob(F-statistic) & 0.000000 & & \\
\hline \hline
\end{tabular}

F-statistic $(84,45446)>\mathrm{F}$ Tabel $(2,77)$. F tabel tingkat $5 \%$ df $1(\mathrm{k}-1)=3$ dan $\mathrm{df2}(\mathrm{n}-\mathrm{k})=56$. Nilai Prob(F-statistic) 84,45446 $<0,05$ maka disimpulkan $\mathrm{HO}$ diterima, bahwa variabel variabel bebas PER, DER dan DPR secara bersama-sama memiliki pengaruh terhadap PBV

b. Uji Adjusted R-squared (Koefisien Determinasi)

\begin{tabular}{lrll}
\hline \hline R-squared & 0.971578 & Mean dependent var & 9.100167 \\
Adjusted R-squared & 0.960074 & S.D. dependent var & 16.66315 \\
S.E. of regression & 3.329554 & Akaike info criterion & 5.486879 \\
Sum squared resid & 465.6090 & Schwarz criterion & 6.115182 \\
Log likelihood & -146.6064 & Hannan-Quinn criter. & 5.732643 \\
F-statistic & $\mathbf{8 4 . 4 5 4 4 6}$ & Durbin-Watson stat & 3.904195 \\
Prob(F-statistic) & 0.000000 & & \\
\hline \hline
\end{tabular}

Adjusted R-squared sebesar 0,971578, artinya variasi perubahan naik turunnya Nilai Perusahaan dapat dijelaskan oleh PER, DER dan DPR sebesar $97,15 \%$, sisanya $2,85 \%$ dijelaskan oleh variabel-variabel lain yang tidak diteliti dalam penelitian ini

c. Uji T

\begin{tabular}{cccrc} 
Variable & Coefficient & Std. Error & t-Statistic & Prob. \\
\hline \hline C & -1.853327 & 2.071302 & -0.894764 & 0.3760 \\
PER & 0.225927 & 0.073504 & 3.073674 & 0.0037 \\
DER & 7.969930 & 1.778899 & 4.480260 & 0.0001 \\
DPR & 0.135724 & 0.804664 & 0.168672 & 0.8669 \\
\hline \hline
\end{tabular}

Effects Specification

1) t-statistic PER 3,073674, t tabel tingkat 5\% df(n-k)=56 yaitu 2,00324 . dengan demikian t-statistic PER $(3,073674)>t$ Tabel $(2,00324)$ dan nilai prob $0,0037<0,05$. Disimpulkan PER berpengaruh positif terhadap Nilai Perusahaan

2) t-statistic DER 4,480260 t tabel tingkat $5 \% \mathrm{df}(n-k)=56$ yaitu 2,00324. dengan demikian t-statistic DER $(4,480260)>t$ Tabel $(2,00324)$ dan nilai prob $0,0001<0,05$. Disimpulkan DER berpengaruh terhadap Nilai Perusahaan

3) t-statistic DPR 0,168672, t tabel tingkat 5\% df(n-k) = 56 yaitu 2,00324. dengan demikian t-statistic DPR $(0,168672)<\mathrm{t}$ Tabel $(2,00324)$ dan nilai prob 0,8669 >0,05. Disimpulkan DPR tidak memiliki pengaruh terhadap Nilai Perusahaan

6. Persamaan Model Regresi Data Panel

Penelitian dengan regresi data panel ini digunakan untuk melihat pengaruh antara variabel independen terhadap variabel dependen. Berdasarkan hasil Fixed Effect Model dapat diketahui bahwa persamaan regresi data panel sebagai berikut : 


$$
\begin{aligned}
& \mathrm{PBV}=-1,853327+0,225927 \mathrm{PER}+ \\
& 7,969930 \mathrm{DER}+0,135724 \mathrm{DPR}+\text { €it }^{2}
\end{aligned}
$$

Dari persamaan regresi tersebut, dapat dijelaskan:

a. Nilai (constant) sebesar 1,853327 hal ini berarti jika variabel independen sama dengan nol, maka nilai perusahaan turun sebesar 1,853327

b. Keputusan Investasi menujukan angka sebesar 0,225927 yang berarti jika keputusan pendanaan dan kebijakan dividen konstan, maka setiap peningkatan keputusan innvestasi sebanyak $1 \%$ akan meningkatkan nilai perusahaan sebesar 0,225927

c. Keputusan Pendanaan menunjukan angka 7,96993 yang berarti jika keputusan investasi dan kebijakan dividen konstan, maka setiap peningkatan keputusan pendanaan sebanyak $1 \%$ akan meningkatkan nilai perusahaan sebesar 7,96993

d. Kebijakan Dividen menunjukan angka 0,135724 yang berarti jika keputusan investasi dan keputusan pendanaan konstan, maka setiap peningkatan kebijakan dividen sebanyak $1 \%$ akan meningkatkan nilai perusahaan sebesar 0,135724

7. Interpretasi Hasil

a. Keputusan Investasi dengan nilai koefisien 0,225927 dan nilai Prob $0,0037<\alpha$ menunjukkan bahwa $\mathrm{H} 1$ diterima, maka kesimpulannya adalah keputusan investasi berpengaruh terhadap nilai perusahaan. Hasil penelitian ini sesuai penelitian yang dilakukan Erysa Septarin (2014) yang menyatakan keputusan investasi berpengaruh positif terhadap nilai perusahaan.

b. Keputusan Pendanaan dengan nilai koefisien 7,96993 dan nilai Prob 0,0001 < a menunjukkan bahwa $\mathrm{H} 2$ diterima, maka kesimpulannya adalah keputusan pendanaa berpengaruh terhadap nilai perusahaan. Hasil penelitian ini sesuai dengan penelitian yang dilakukan oleh Luh Putu Utami, I Wayan Pradnyantha (2018) yang menyatakan bahwa keputusan pendanaan berpengaruh terhadap nilai perusahaan

c. Kebijakan Dividen dengan nilai koefisien 0,135724 dan nilai Prob 0,8669 > a menunjukkan bahwa H3 ditolak, maka kesimpulannya adalah Kebijakan Dividen tidak berpengaruh terhadap Nilai Perusahaan. Hasil penelitian ini sesuai dengan penelitian yang dilakukan oleh Inasfatin (2017) yang menyatakan bahwa kebijakan dividen tidak berpengaruh terhadap nilai perusahaan.

\section{KESIMPULAN}

Berdasarkan hasil penelitian, maka dapat ditarik kesimpulan sebagai berikut :

1. Secara simultan (Uji F) variabel keputusan investasi, keputusan pendanaan, dan kebijakan dividen secara bersama-sama memiliki pengaruh terhadap nilai perusahaan. 
2. Secara parsial (Uji t) variabel keputusan dividend dan keputusan pendanaan berpengaruh terhadap nilai perusahaan, sedangkan variabel kebijakan dividen tidak berpengaruh terhadap kebijakan dividen

\section{DAFTAR PUSTAKA}

Ghaesani Nurviandaa, Yulianib, Reza Ghasarmac (2018). Pengaruh Keputusan Investasi, KeputusanPendanaandan Kebijakan Dividen Terhadap Nilai Perusahaan

Muhson, Ali. (2006) TEKNIK ANALISIS KUANTITATIF, URL http://staffnew.uny.ac.id/upload/132232818/pendidikan/Analisis+Ku antitatif.pdf

Siti Yulita Aulia (2019), pengaruh keputusan investasi, keputusan pendanaan, dan kebijakan dividen terhadap nilai perushaan(pada perushaan manufaktur sector industry barang konsumsi di bursa efek Indonesia periode 2015-2018)

Eksandy, Arry. (2018). Metode Penelitian Akuntansi. Tangerang:Universitas Muhammadiyah tangerang Hal79-391

Bursa Efek Indonesia, Laporan Keuangan Tahunan 2016, 2017, 2018, 2019 (http://www.idx.co.id)

Setyowati, Sulis and, Dra.Nursiam,SE,M.,Si (2016) Pengaruh Keputusan Investasi, Keputusan Pendanaan, Kebijakan Dividen Dan Tingkat Profitabilitas Terhadap Nilai Perusahaan (Studi Empiris Pada Perusahaan Non Manufaktur Yang Terdaftar Di Bursa Efek Indonesia Periode 2011-2013).

Luh Putu Utami Kartika Dewi, I Wayan Pradnyantha Wirasedana (2018). Pengaruh Keputusan Investasi, Keputusan Pendanaan, Kebijakan Dividen dan Tingkat Inflasi terhadap Nilai Perusahaan

Inasfatin Indriawati, Marsiska Ariesta, Edi Budi Santoso (2018), PENGARUH PROFITABILITAS,KEPUTUSAN INVESTASI, PERTUMBUHAN PERUSAHAAN TERHADAP NILAI PERUSAHAAN DENGAN KEBIJAKAN DEVIDEN SEBAGAI VARIABEL INTERVENING PADA PERUSAHAAN MANUFAKTUR FOOD AND BEVERAGEYANG TERDAFTAR DI BURSA EFEK INDONESIA TAHUN 2012 -2016

Riadi, Muchlisin. (25 November 2017). Pengertian, Jenis dan Pengukuran Nilai Perusahaan.

https://www.kajianpustaka.com/2017/11/pengertian-jenis-danpengukuran-nilai-perusahaan.html

Merina . Salama, Paulina Van Rate, Victoria N. Untu (2019), PENGARUH KEPUTUSAN INVESTASI, KEPUTUSAN PENDANAAN DAN KEBIJAKAN DIVIDEN TERHADAP NILAI PERUSAHAAN PADA INDUSTRI PERBANKAN YANG TERDAFTAR DI BEI PERIODE 2014-2017 